\title{
Prevalence of high HDL-Cholesterol and its Associated Factors Among Childbearing Age Tunisian women: A Cross-Sectional Study
}

\section{Fatma Ben Cherifa}

National Institute of Nutrition and Food Technology

Jalila El Ati

National Institute of Food Science and Technology

Radhouene Doggui

National Institute of Food Science and Technology

Fayçal Hellal

National Institute of Applied Sciences and Technology

Myriam El Ati-Hellal ( $\nabla$ mfh22002@yahoo.fr)

Preparatory Institute of scientific and technical study https://orcid.org/0000-0002-3895-9714

\section{Research}

Keywords: High HDL-C, prevalence, risk factors, Childbearing age Tunisian women

Posted Date: January 19th, 2021

DOI: https://doi.org/10.21203/rs.3.rs-149173/v1

License: (9) This work is licensed under a Creative Commons Attribution 4.0 International License. Read Full License 


\section{Abstract}

Background: The protective role of high HDL-C against cardiovascular risk has been questioned recently. Due to the increasing trend of CVD in Tunisia, this study aimed to determine the prevalence of high HDL-C and its associated factors in childbearing age Tunisian women.

Methods: A cross-sectional survey was conducted among a subsample of 1689 women, aged 20 to $49 \mathrm{y}$ in the Great Tunis region. Data on socio-demographic and lifestyle factors were collected by a questionnaire. Overall adiposity was assessed by BMI. All biological variables were assayed in blood samples coated with EDTA by enzymatic methods. Stata software (2015) was used for data management and statistical analysis.

Results: High HDL-C values were recorded in $26.6 \%$ of selected women. After adjustment for all sociodemographic and lifestyle factors, age, hypertension and smoking were negatively associated with high HDL-C levels while family history of cancer was positively associated with high HDL-C in women.

Conclusions: Additional investigation on the relationship between high HDL-C and cancer risk should be performed due to controversial results.

\section{Background}

Cardiovascular diseases (CVD) are the leading cause of deaths worldwide (1). In Tunisia, a Middle East and North African (MENA) country with eleven million inhabitants, CVD are responsible of $23.9 \%$ and $28.7 \%$ of deaths for men and women, respectively (2). Several epidemiological studies have shown an inverse and independent association between high density lipoprotein cholesterol (HDL-C) and CVD $(3,4)$. The protective effect of HDL-C is mainly due to its transport of excess cholesterol from peripheral tissues to the liver. This pathway is called the reverse cholesterol transport system (RCT) (5-7). Additional protective properties of HDL-C include its antioxidant, anti-inflammatory, anti-infectious and antithrombotic potential (8-10). Recently, the prognostic importance of HDL-C as a specific risk factor for CVD has been questioned since many therapies attempting to increase HDL-C failed to improve clinical outcomes $(10,11)$. Moreover, other studies reported that extremely high levels of HDL-C are associated with high mortality risk (12-14).

Due to the increasing trend of CVD in Tunisia, this study aimed to estimate the prevalence of HDL-C and to investigate the associations between high HDL-C levels and socio-demographic, metabolic and lifestyle factors in childbearing age Tunisian women.

\section{Methods}

\section{Sampling and study population}


A cross-sectional survey was carried out between March 2009 and January 2010 in the Greater Tunis region, a mainly urban area around the capital city (2.5 million inhabitants of whom $92 \%$ live in urban areas and $8 \%$ in rural areas). Sampling was carried out by the National Institute of Statistics, according to a stratified random survey in two stages. Totally, 76 districts were selected first according to the governorate of residence, then according to the environment (urban and rural). From each district, 20 households were randomly selected and all persons aged 6 mo to $49 \mathrm{y}$ were included. In the present study, a sub-sample of non-pregnant women aged 20 to $49 \mathrm{y}$ old was used.

\section{Socio-economic and demographic variables}

Data on the woman's age, marital status, parity, menopause, level of education, lifestyle (smoking, alcoholism and sport activity), occupation and household size were collected by a questionnaire. An economic level score for the household was calculated from six variables describing the dwelling and eleven variables coding household ownership of appliances. The total score obtained per household is coded in terciles corresponding to "low", "medium" and "high" economic level (15).

\section{Anthropometric variables}

Measurements of height, weight and waist circumference were performed according to standardized procedures (16). Height was measured to the nearest $0.1 \mathrm{~cm}$ with a stadiometer. Body weight was measured to the nearest $0.1 \mathrm{~kg}$. Waist circumference (WC) was measured to the nearest $0.1 \mathrm{~cm}$ using a metric fiberglass tape. Overall adiposity was assessed by BMI (weight $(\mathrm{kg}) /$ height $^{2}\left(\mathrm{~m}^{2}\right)$ ). BMI was categorized as underweight $<18.5 \mathrm{~kg} / \mathrm{m}^{2}$, overweight $\geq 25 \mathrm{~kg} / \mathrm{m}^{2}$ and obese $\geq 30 \mathrm{~kg} / \mathrm{m}^{2}$.

\section{Biological variables}

Analysis

$5 \mathrm{ml}$ blood samples were collected on tubes coated with the anticoagulant Ethylene Diamine Tetra-Acetic (EDTA). All samples were kept at $4-5{ }^{\circ} \mathrm{C}$ and sent the same day to the Clinical Biology Laboratory of the National Institute of Nutrition and Food Technology then centrifuged at $4000 \mathrm{~g}$ for 10 minutes and stored at $-20^{\circ} \mathrm{C}$ until analysis. Blood pressure (BP) was measured at rest, twice and at a time interval of at least 15 minutes, using a BP monitor. Fasting blood glucose, total cholesterol (TC), triglyceridemia, high density lipoprotein cholesterolemia (HDL-C), low density lipoprotein cholesterolemia (LDL-C) and apoliproteins A-I (ApoA-I) and B (ApoB), were assayed by enzymatic methods on Synchron analyzer and calibrator, using Beckman reagents. The accuracy was evaluated by quality control samples (BioRad).

Threshold values

Hypertension was defined as having an average systolic blood pressure (SBP) $\geq 140 \mathrm{~mm} \mathrm{Hg}$ and/or diastolic blood pressure (DBP) $\geq 90 \mathrm{~mm} \mathrm{Hg}$ or taking medication for high BP (17). Diabetes mellitus was defined as a fasting glucose level $\geq 126 \mathrm{mg} / \mathrm{dL}$ (7 mmol/L) and/or the use of antidiabetic treatment(18). A HDL-C level of $<50 \mathrm{mg} / \mathrm{dL}$ in women was considered as low, while a HDL-C level of $\geq 60 \mathrm{mg} / \mathrm{dL}$ was considered as high (19). Metabolic syndrome was present in the case of women central obesity (WC > 
$80 \mathrm{~cm}$ ) and at least two of the following risk factors: SBP $\geq 130 \mathrm{~mm} \mathrm{Hg}$ or DBP $\geq 85 \mathrm{~mm} \mathrm{Hg}$ or antihypertensive treatment; glucose $\geq 1 \mathrm{~g} / \mathrm{L}(5.6 \mathrm{mmol} / \mathrm{dL})$ or diagnosis of type 2 diabetes mellitus; triglyceridemia $\geq 1,5 \mathrm{~g} / \mathrm{L}(1.7 \mathrm{mmol} / \mathrm{L})$ or treatment of high triglyceridemia (20). Other CVD risk factors were obtained with ratios of TC/ HDL-C and Apo-B/Apo-A1 higher than 4.5 and 1, respectively $(21,22)$.

\section{Data management and statistical analysis}

Data entry including quality checks as well as validation by double entry was performed with EpiData Software version 3.1(23). Stata software (24) was used for data management and statistical analysis. Results are shown as mean \pm standard error. The association between categorical variables was evaluated by the test of chi-square. The association of high HDL-C with the different cofactors was assessed by calculating odds-ratio (OR), after the selection of an appropriate reference category. For tests and confidence intervals an alpha threshold of $5 \%$ was chosen.

\section{Results}

\section{General characteristics of subjects}

The survey was conducted among 1689 women, aged 20 to 49 y (average age $36.1 \pm 0.3 \mathrm{y}$ ), of which $67.7 \%$ were married and $32.2 \%$ were single, separated, divorced or widowed at the time of the survey. The majority of women (40.2\%) were multiparous, with 3 or more children while $26.9 \%$ had between 1 and 2 children. Only $10.9 \%$ of women had never attended school, $53.2 \%$ had reached secondary or university level and $32.8 \%$ reported working outside.

\section{Characteristics of women according to HDL-C levels}

The average HDL-C concentration in childbearing age Tunisian women was $1.36 \pm 0.02 \mathrm{mmol} / \mathrm{L}$ (52.6 \pm $0.8 \mathrm{mg} / \mathrm{dL}$ ). High HDL-C values were recorded in $26.6 \%$ of subjects, while $14.3 \%$ were with low HDL-C concentrations. Table 1 displays the characteristics of the selected participants according to HDL-C levels. Age as well as area of living, menopause, professional activity, smoking, drinking alcohol, sport activity, diabetes, metabolic syndrome, lipid-lowering treatment, family history of CVD, family history of hypertension, family history of diabetes, family history of obesity, fasting blood glucose and LDL-C had no effects on HDL-C concentrations. However, marital status, parity, economic level, overweight, obesity, abdominal obesity, hypertension, family history of cancer, TC, triglyceridemia, TC/HDL-C ratio, ApoA-I, ApoB, ApoA-I/ApoB ratio, SBP and DBP were significantly associated with HDL-C values. Results of multivariate regression analysis (Fig. 1) revealed that age (30-39 y) (OR = 0.49 [0.32-0.73]), age (40-49y) $(\mathrm{OR}=0.7$ [0.49-1.00]), hypertension (OR = 0.56 [0.38-0.83]), smoking $(\mathrm{OR}=0.56[0.32-0.98])$ and family history of cancer $(\mathrm{OR}=1.53[1.11-2.11])$ were the only factors correlated with HDL-C levels in childbearing age Tunisian women. 
Table 1

Characteristics of Tunisian women according to HDL-C levels

\begin{tabular}{|c|c|c|c|}
\hline Variable & $\begin{array}{l}\text { High HDL-C } \\
\geq 60 \mathrm{mg} / \mathrm{dL}\end{array}$ & $\begin{array}{l}\text { Normal and low HDL-C } \\
<60 \mathrm{mg} / \mathrm{dL}\end{array}$ & $P^{1}$ value \\
\hline \multicolumn{4}{|l|}{ Age $(\%)$} \\
\hline $20-29 y$ & 32.0 & 28.1 & \multirow[t]{3}{*}{0.35} \\
\hline $30-39 y$ & 28.2 & 31.3 & \\
\hline $40-49 y$ & 39.8 & 40.6 & \\
\hline \multicolumn{4}{|l|}{ Area of living (\%) } \\
\hline Rural & 6,8 & 7,5 & \multirow[t]{2}{*}{0.68} \\
\hline Urbain & 93,2 & 92,5 & \\
\hline \multicolumn{4}{|l|}{ Marital status (\%) } \\
\hline Otherb & 61,4 & 69,2 & \multirow[t]{2}{*}{0.005} \\
\hline Married & 38,6 & 30,8 & \\
\hline \multicolumn{4}{|l|}{ Parity (\%) } \\
\hline 3 and more children & 34,8 & 42,2 & \multirow[t]{3}{*}{0,029} \\
\hline 1 or 2 children & 26,6 & 26,9 & \\
\hline O children & 38,5 & 30,9 & \\
\hline \multicolumn{4}{|l|}{ Menopause (\%) } \\
\hline No & 90.5 & 92.9 & \multirow[t]{2}{*}{0.081} \\
\hline Yes & 9.5 & 7.1 & \\
\hline \multicolumn{4}{|l|}{ Level of education (\%) } \\
\hline No schooling & 7,7 & 12,0 & \multirow[t]{3}{*}{$<10^{-4}$} \\
\hline Primary and secondary school & 28,3 & 38,8 & \\
\hline Secondary complete and graduate & 64,0 & 49,2 & \\
\hline \multicolumn{4}{|l|}{ Professional activity (\%) } \\
\hline No & 33,9 & 32,4 & \multirow[t]{2}{*}{0,67} \\
\hline Yes & 66,1 & 67,6 & \\
\hline \multicolumn{4}{|l|}{ Economic level (\%) } \\
\hline Low & 42,5 & 35,1 & 0,007 \\
\hline
\end{tabular}




\begin{tabular}{|c|c|c|c|}
\hline Variable & $\begin{array}{l}\text { High HDL-C } \\
\geq 60 \mathrm{mg} / \mathrm{dL}\end{array}$ & $\begin{array}{l}\text { Normal and low HDL-C } \\
<60 \mathrm{mg} / \mathrm{dL}\end{array}$ & $P^{1}$ value \\
\hline Medium & 31,3 & 34,9 & \\
\hline High & 26,2 & 30,0 & \\
\hline \multicolumn{4}{|l|}{ Smoking (\%) } \\
\hline No & 94,8 & 93,6 & 0.21 \\
\hline Yes & 5,2 & 6,4 & \\
\hline \multicolumn{4}{|l|}{ Drinking alcohol (\%) } \\
\hline No & 100 & 99,4 & 0.24 \\
\hline Yes & 0 & 0,6 & \\
\hline \multicolumn{4}{|l|}{ Sport activity (\%) } \\
\hline No & 93,2 & 93,8 & \multirow[t]{2}{*}{0.70} \\
\hline Yes & 6.8 & 6.2 & \\
\hline Hypertension (\%) & 4,0 & 6,4 & 0,074 \\
\hline Diabetes Mellitus (\%) & 13,1 & 24,4 & $<10^{-4}$ \\
\hline Metabolic syndrome (\%) & 28,3 & 33,2 & 0,059 \\
\hline Family history of Cancer (\%) & 61,2 & 71,8 & 0,002 \\
\hline Family history of CVD (\%) & 61,9 & 66,1 & 0,17 \\
\hline Family history of Hypertension (\%) & 62,1 & 64,4 & 0,59 \\
\hline Family history of Diabetes (\%) & 60,0 & 57,7 & 0,48 \\
\hline Family history of Obesity (\%) & 55,2 & 54,6 & 0,86 \\
\hline Lipid lowering treatment (\%) & 1,3 & 1,3 & 0,97 \\
\hline Fasting blood glucose $(\mathrm{mmol} / \mathrm{L})^{2}$ & $4,93 \pm 0,08$ & $5,07 \pm 0,06$ & 0,102 \\
\hline $\mathrm{TC}(\mathrm{mmol} / \mathrm{L})$ & $5,17 \pm 0,06$ & $4,62 \pm 0,05$ & $<10^{-4}$ \\
\hline Triglyceridemia $(\mathrm{mmol} / \mathrm{L})$ & $0,89 \pm 0,03$ & $1,12 \pm 0,03$ & $<10^{-4}$ \\
\hline LDL-C (mmol/L) & $2,98 \pm 0,06$ & $2,91 \pm 0,04$ & 0,27 \\
\hline TC/HDL-C & $2,92 \pm 0,04$ & $3,91 \pm 0,04$ & $<10^{-4}$ \\
\hline ApoA-I (mmol/L) & $1,58 \pm 0,03$ & $1,31 \pm 0,02$ & $<10^{-4}$ \\
\hline
\end{tabular}




\begin{tabular}{|lllc|}
\hline Variable & $\begin{array}{l}\text { High HDL-C } \\
\geq 60 \mathrm{mg} / \mathrm{dL}\end{array}$ & $\begin{array}{l}\text { Normal and low HDL-C } \\
<60 \mathrm{mg} / \mathrm{dL}\end{array}$ & $\boldsymbol{P}^{1}$ value \\
\hline ApoB $(\mathrm{mmol} / \mathrm{L})$ & $0,79 \pm 0,02$ & $0,86 \pm 0,02$ & 0,003 \\
\hline ApoB/Apo Al & $0,50 \pm 0,03$ & $0,66 \pm 0,02$ & $<10^{-4}$ \\
\hline SBP & $119,5 \pm 0,9$ & $122,8 \pm 0,8$ & 0,001 \\
\hline DBP & $74,5 \pm 0,5$ & $76,85 \pm 0,51$ & $10^{-4}$ \\
\hline ': $P$ value for logistic regression models accounting for survey design among categories of variable. & \\
\hline 2: Values are mean \pm standard deviation. & & \\
\hline
\end{tabular}

\section{Discussion}

The mean HDL-C level found in this study $(52.6 \pm 0.8 \mathrm{mg} / \mathrm{dL})$ is in the normal range (between 50 and $60 \mathrm{mg} / \mathrm{dL}$ ) (19) and similar to that reported in a previous Tunisian research on dyslipidemia, conducted among 1484 women aged 35-70 y old, in the same sampling area (25). Compared to data registered elsewhere, the mean HDL-C value in childbearing age Tunisian women is higher than that recorded in Japanese (26), Korean (27), Hispanic and African American women (28) and lower than that reported in Canadian (29), Danish (14) and US women (30). The differences in HDL-C levels between various races and ethnic groups may in part be due to genetic factors but the role of behavioral, environmental and anthropometric covariates seems to be important too $(31,32)$.

Age appears to be an independent negative risk factor that can affect HDL-C levels in Tunisian women. This is consistent with previous studies reporting a decrease of HDL-C with age in women $(27,33)$. Many factors could explain this phenomenon such as the frequency of insulin resistance and impaired lipolysis at advanced age that could affect the RCT. Inflammatory processes in aged people as well as hormonal changes are other possible causes of decline in HDL-C with age (34).

Parity and marital status influenced negatively the HDL-C concentration in Tunisian women. After pregnancy, the level of cholesterol bound to HDL particles tends to decrease, which explains the tendency of multiparous women to have lower circulating HDL-C levels than women who have never given birth. These changes in circulating cholesterol levels are likely due to changes in estrogen levels which vary throughout a woman's genital life $(35,36)$.

Menopause didn't affect circulating HDL-C levels. This result is in contradiction with those of several authors showing that a worse lipid profile is observed in postmenopausal women in comparison to premenopausal ones due to hormonal changes involving the decrease in estrogen level and increase in luteinizing hormone and follicle stimulating hormone levels $(33,37)$. In our study, the majority of women 
(92.3\%) are premenopausal, which could explain the absence of relationship between menopause and lipid profile.

In this study, women with high HDL-C levels are more educated and have a lower socioeconomic status than those with mean or low levels of HDL-C. Agongo et al. (2018) (38) found a positive significant association between formal education and socioeconomic status with HDL-C levels in women from rural northern Ghana, while no significant association was found between HDL-C and socioeconomic status of Korean women (27). The mechanisms of association between HDL-C and socioeconomic status are complex due to the influence of lifestyle factors and dietary habits as well as stress variations by social class (39).

Results on the associations between HDL-C levels and lifestyle factors (physical activity, alcohol consumption and smoking) showed that smoking was the only negative risk factor of HDL-C in Tunisian women. Research has shown that physical activity and moderate alcohol consumption are positively correlated with HDL-C contrarily to smoking. According to King et al. (1995), a regular physical activity increases the HDL-C level by 3 to 9 percent in healthy sedentary persons (40). This increase depends on exercise frequency and intensity and is attributed to the stimulation of the production of pre- $\beta$ HDL-C and RCT (41). The effects of smoking on HDL-C are dose dependent and reversed upon smoking cessation. Nakamura et al. (2020), found that in both men and women, current smokers had significantly $(p<0.001)$ lower HDL-C than non-smokers (-7.3\%, -4.3\%) (42). Likewise, Jain and Ducatman (2018) reported lower HDL-C in smokers than in non-smokers (48.8 vs $51.4 \mathrm{mg} / \mathrm{dL}, \mathrm{p}<0.01)$ (43). Alcohol consumption in moderation raises the concentration of HDL-C, possibly by increasing cellular cholesterol efflux and plasma cholesterol esterification (44). Brien at al. (2011) reported an increase of HDL-C by $0.1 \mathrm{mmol} / \mathrm{L}$ with a quantity of alcohol of about $30 \mathrm{~g} /$ day (45). However, the cardioprotective effect of raised HDL-C by alcohol consumption is largely unknown.

While the univariate analysis showed a higher prevalence of chronic diseases in women with normal or low HDL-C levels (overweight, obesity, abdominal obesity and hypertension) than the counterpart group, the multivariate regression analysis revealed that hypertension was the only negative risk factor of HDL-C in Tunisian women. Due to epidemiological and nutritional transition, the prevalence of overall obesity and abdominal obesity in Tunisian women has increased drastically during the last decades (46). In this study, the overall obesity affected the third of Tunisian women and the abdominal obesity concerned almost the half, with a decreasing trend with HDL-C levels. The negative associations between obesity and HDL-C have long been reported and were attributed to the potential role of HDL-C or ApoA-I on adipose tissue content regulation $(47,48)$. Hypertension is a well-established risk factor for CVD and is strongly associated with dyslipidemia, a group of metabolic derangements including low HDL-C levels. This association occurs at the vascular endothelial level leading to an increase of oxidative stress and endothelial dysfunction (49). The inverse association between HDL-C and hypertension was reported elsewhere (50). Halperin et al. (2006) found that men in the highest quintile of HDL-C had a $32 \%$ decreased risk of developing hypertension compared with those in the lowest quintile (51). Likewise, 
Tohidi et al. (2012) found that women with HDL-C level between 1.0 and $1.5 \mathrm{mmol} \mathrm{L}^{-1}$ had $33 \%$ lower risk of hypertension compared with those having HDL-C levels $<1 \mathrm{mmol} \mathrm{L}^{-1}(52)$.

Family history of chronic diseases (CVD, hypertension, diabetes, obesity) was not correlated with HDL-C levels in this study, except the family history of cancer. In addition, the intake of lipid-lowering drugs is evenly divided between participants. According to Steyn et al. (1989), women with high levels of HDL-C were less likely to have a history of hypertension or diabetes (53) than those with low HDL-C concentrations. Opoku et al. (2019) reported negative significant associations of the history of coronary heart disease and the history of stroke with HDL-C in Chinese women (50). In the Bogalusa Heart Study, children with fathers' history of myocardial infraction had low ApoA-I levels and a high ApoB/ApoA-I ratio, whereas their HDL-C levels were not outside normal limits (54). In this study, family history of cancer revealed an inverse association with HDL-C levels between the univariate and the multivariate analysis. After adjustment for all sociodemographic, metabolic and lifestyle factors, the family history of cancer was a strong positive predictor of HDL-C in Tunisian women. Similar findings were observed in a cohort study on US veterans, which reported a slight increase in cancer mortality among participants with high HDL-C levels (> $50 \mathrm{mg} / \mathrm{dL}$ ). However, other epidemiological studies reported that a low HDL-C level may be a risk of cancer deaths or a prognostic factor of many types of cancer in obese subjects (29). These controversial results need further investigations on the relationship between HDL-C and cancer disease.

Significant differences were noticed between biological characteristics in women with high HDL-C levels and the counterpart group. Triglyceridemia, ApoB, TC/HDL-C and ApoB/ApoA-I ratios, SBP and DBP were lower in women with high HDL-C concentrations contrary to TC and ApoA-I levels. Increased plasma triglyceride levels have been associated with an increased risk of CVD even when HDL-C levels were adjusted for (55). ApoA-l is the major structural and functional HDL protein which accounts for approximately $70 \%$ of total HDL protein and is significantly associated with HDL particles (56). However, more than $90 \%$ of all ApoB in blood is found in LDL (57). Clinical studies have reported that elevated ApoB levels, an increased apoB/apoA-I ratio and low levels of apoA-I were better predictors of cardiovascular events than LDL-C, TC and triglyceride levels even in patients receiving statins (57). SBP and DBP were lower in women with high HDL-C levels. This result confirms the protective role of HDL-C against risk factors of CVD such as raised blood pressure or hypertension. Despite the significant differences in biological characteristics between women with high HDL-C and those with normal or low HDL-C, all mean concentrations were within the normal range for both groups in our study.

\section{Strengths And Limitations}

This study has several strengths in terms of sample size and the evaluation of a large set of covariates as potential risk factors for high HDL-C levels in Tunisian women. The limitations concern the lack of dietary information that could affect HDL-C levels, especially fat intake, and the cross-sectional study which prevents from establishing causal relationships.

\section{Conclusions}


The prevalence of high HDL-C and its associated physical, sociodemographic, biological and lifestyle factors were assessed in a cross-sectional study conducted among childbearing age Tunisian women. Almost the quarter of studied women were with high HDL-C levels. They were younger, more educated and had a lower socioeconomic status than those with mean or low levels of HDL-C. Age, hypertension and smoking were independent negative risk factors of high HDL-C in women while family history of cancer was positively associated with high HDL-C levels. Due to controversial findings on the association between high HDL-C and cancer disease, further investigations should be performed in this domain.

\section{Declarations}

\section{Ethics approval and consent to participate}

During this study, all applicable institutional and governmental regulations concerning the ethical use of human volunteers were respected. The project and the survey protocol were reviewed and approved by the Ethical Committee of the National Institute of Nutrition and Food Technology (decision on February $7^{\text {th }} 2009$ ) and the Tunisian National Council of Statistics, which assigned the identifier number 02/2009. After being thoroughly informed on the purpose, requirements, and procedures of the survey, all women gave their ethical approval and consent. All data were handled anonymously during analysis. This study is registered in the ClinicalTrials.gov registry. The Identifier number is NCT01844349.

\section{Consent for publication}

Not applicable

\section{Availability of data and materials}

The datasets generated during and/or analysed during the current study are available from the corresponding author on reasonable request.

\section{Competing interests}

The authors declare that they have no competing interests

\section{Funding}

This study was supported by the CORUS programme of the French Ministry of Overseas and European Affairs, as part of the 'Obe-Maghreb' research project (Contract Corus 6028-2); Institut de Recherche pour le Développement (IRD), France; The National Institute of Nutrition and Food Technology (INNTA), Tunisia.

\section{Authors' contributions}

All authors conceived and designed the experiments. Data collection and analysis was performed by RD, $\mathrm{FH}$ and FBC. JEA and MEAH supervised the field survey, the collection and acquisition of data. FBC and 
MEAH wrote the article. All authors read and approved the final manuscript.

Acknowledgements

The authors thank all members of the INNTA study and planning team for their valuable contribution to fieldwork and data entry.

\section{References}

1. WHO. Global action plan for the prevention and control of noncommunicable diseases 2013-2020. In: Organization WH, editor. Geneva, Switzerland2013.

2. NIS. National statistics on the causes of death in. Tunisia 2015 and 2017 (in french). Tunisia: National Institute of Statistics; 2020.

3. Gordon DJ, Probstfield JL, Garrison RJ, Neaton JD, Castelli WP, Knoke JD, et al. High-density lipoprotein cholesterol and cardiovascular disease. Four prospective American studies. Circulation. 1989;79(1):8-15.

4. Emerging Risk Factors C, Di Angelantonio E, Sarwar N, Perry P, Kaptoge S, Ray KK, et al. Major lipids, apolipoproteins, and risk of vascular disease. JAMA. 2009;302(18):1993-2000.

5. Assmann G, Gotto AM. Jr. HDL cholesterol and protective factors in atherosclerosis. Circulation. 2004;109(23 Suppl 1):III8-14.

6. Marz W, Kleber ME, Scharnagl H, Speer T, Zewinger S, Ritsch A, et al. HDL cholesterol: reappraisal of its clinical relevance. Clin Res Cardiol. 2017;106(9):663-75.

7. Marz W, Kleber ME, Scharnagl H, Speer T, Zewinger S, Ritsch A, et al. [Clinical importance of HDL cholesterol]. Herz. 2017;42(1):58-66.

8. Brites F, Martin M, Guillas I, Kontush A. Antioxidative activity of high-density lipoprotein (HDL): Mechanistic insights into potential clinical benefit. BBA Clin. 2017;8:66-77.

9. Tosheska Trajkovska K, Topuzovska S. High-density lipoprotein metabolism and reverse cholesterol transport: strategies for raising HDL cholesterol. Anatol J Cardiol. 2017;18(2):149-54.

10. Estrada-Luna D, Ortiz-Rodriguez MA, Medina-Briseno L, Carreon-Torres E, Izquierdo-Vega JA, Sharma A, et al. Current Therapies Focused on High-Density Lipoproteins Associated with Cardiovascular Disease. Molecules. 2018;23(11).

11. Talbot D, Delaney JAC, Sandfort V, Herrington DM, McClelland RL. Importance of the lipid-related pathways in the association between statins, mortality, and cardiovascular disease risk: The MultiEthnic Study of Atherosclerosis. Pharmacoepidemiol Drug Saf. 2018;27(4):365-72.

12. Singh $K$, Rohatgi A. Examining the paradox of high high-density lipoprotein and elevated cardiovascular risk. J Thorac Dis. 2018;10(1):109-12.

13. Oh IH, Hur JK, Ryoo JH, Jung JY, Park SK, Yang HJ, et al. Very high high-density lipoprotein cholesterol is associated with increased all-cause mortality in South Koreans. Atherosclerosis. 2019;283:43-51. 
14. Madsen CM, Varbo A, Nordestgaard BG. Extreme high high-density lipoprotein cholesterol is paradoxically associated with high mortality in men and women: two prospective cohort studies. Eur Heart J. 2017;38(32):2478-86.

15. El Ati J, Traissac P, Delpeuch F, Aounallah-Skhiri H, Beji C, Eymard-Duvernay S, et al. Gender obesity inequities are huge but differ greatly according to environment and socio-economics in a North African setting: a national cross-sectional study in Tunisia. PloS one. 2012;7(10):e48153.

16. WHO. Physical Status: the Use and Interpretation of Anthropometry. Geneva: World Health Organization; 1995.

17. Whitworth JA. World Health Organization ISoHWG. 2003 World Health Organization (WHO)/International Society of Hypertension (ISH) statement on management of hypertension. J Hypertens. 2003;21(11):1983-92.

18. Report of the Expert Committee on the Diagnosis and Classification of Diabetes Mellitus. Diabetes Care. 1997;20(7):1183-97.

19. National Cholesterol Education Program Expert Panel on Detection E. Treatment of High Blood Cholesterol in A. Third Report of the National Cholesterol Education Program (NCEP) Expert Panel on Detection, Evaluation, and Treatment of High Blood Cholesterol in Adults (Adult Treatment Panel III) final report. Circulation. 2002;106(25):3143-421.

20. Alberti KG, Zimmet P, Shaw J. Metabolic syndrome-a new world-wide definition. A Consensus Statement from the International Diabetes Federation. Diabet Med. 2006;23(5):469-80.

21. Walldius G, Jungner I, Holme I, Aastveit AH, Kolar W, Steiner E. High apolipoprotein B, low apolipoprotein A-I, and improvement in the prediction of fatal myocardial infarction (AMORIS study): a prospective study. Lancet. 2001;358(9298):2026-33.

22. Lavie CJ, Milani RV, Ventura HO. Obesity and cardiovascular disease: risk factor, paradox, and impact of weight loss. J Am Coll Cardiol. 2009;53(21):1925-32.

23. Epidata. EpiData Data Entry, Data Management and basic Statistical Analysis System. In: Lauritsen J, editor. Odense. Denmark: Epidata Association; 2008.

24. StataCorp. Stata Statistical Software: Release 14.0. College Station. Texas: StataCorp LP; 2015.

25. Hadj-Taieb S, Elasmi M, Hammami MB, Marrakchi R, Amani K, Omar S, et al. Dyslipidemia in the Greater Tunis population: prevalence and determinants. Clin Lab. 2012;58(7-8):763-70.

26. Soyama Y, Miura K, Morikawa Y, Nishijo M, Nakanishi Y, Naruse Y, et al. High-density lipoprotein cholesterol and risk of stroke in Japanese men and women: the Oyabe Study. Stroke. 2003;34(4):863-8.

27. Kim SM, Han JH, Park HS. Prevalence of low HDL-cholesterol levels and associated factors among Koreans. Circ J. 2006;70(7):820-6.

28. Young KA, Maturu A, Lorenzo C, Langefeld CD, Wagenknecht LE, Chen YI, et al. The triglyceride to high-density lipoprotein cholesterol (TG/HDL-C) ratio as a predictor of insulin resistance, beta-cell function, and diabetes in Hispanics and African Americans. J Diabetes Complications. 2019;33(2):118-22. 
29. Ko DT, Alter DA, Guo H, Koh M, Lau G, Austin PC, et al. High-Density Lipoprotein Cholesterol and Cause-Specific Mortality in Individuals Without Previous Cardiovascular Conditions: The CANHEART Study. J Am Coll Cardiol. 2016;68(19):2073-83.

30. Ford ES, Liu S. Glycemic index and serum high-density lipoprotein cholesterol concentration among us adults. Arch Intern Med. 2001;161(4):572-6.

31. Bentley AR, Chen G, Shriner D, Doumatey AP, Zhou J, Huang H, et al. Gene-based sequencing identifies lipid-influencing variants with ethnicity-specific effects in African Americans. PLoS Genet. 2014;10(3):e1004190.

32. Karthikeyan G, Teo KK, Islam S, McQueen MJ, Pais P, Wang X, et al. Lipid profile, plasma apolipoproteins, and risk of a first myocardial infarction among Asians: an analysis from the INTERHEART Study. J Am Coll Cardiol. 2009;53(3):244-53.

33. Rysz J, Gluba-Brzozka A, Rysz-Gorzynska M, Franczyk B. The Role and Function of HDL in Patients with Chronic Kidney Disease and the Risk of Cardiovascular Disease. Int J Mol Sci. 2020;21(2).

34. Walter M. Interrelationships among HDL metabolism, aging, and atherosclerosis. Arterioscler Thromb Vasc Biol. 2009;29(9):1244-50.

35. Kritz-Silverstein D, Barrett-Connor E, Wingard DL. The relationship between multiparity and lipoprotein levels in older women. J Clin Epidemiol. 1992;45(7):761-7.

36. Lv H, Yang X, Zhou Y, Wu J, Liu H, Wang Y, et al. Parity and serum lipid levels: a cross-sectional study in chinese female adults. Sci Rep. 2016;6:33831.

37. Wang Q, Ferreira DLS, Nelson SM, Sattar N, Ala-Korpela M, Lawlor DA. Metabolic characterization of menopause: cross-sectional and longitudinal evidence. BMC Med. 2018;16(1):17.

38. Agongo G, Nonterah EA, Debpuur C, Amenga-Etego L, Ali S, Oduro A, et al. The burden of dyslipidaemia and factors associated with lipid levels among adults in rural northern Ghana: An AWIGen sub-study. PLoS One. 2018;13(11):e0206326.

39. Muennig P, Sohler N, Mahato B. Socioeconomic status as an independent predictor of physiological biomarkers of cardiovascular disease: evidence from NHANES. Prev Med. 2007;45(1):35-40.

40. King AC, Haskell WL, Young DR, Oka RK, Stefanick ML. Long-term effects of varying intensities and formats of physical activity on participation rates, fitness, and lipoproteins in men and women aged 50 to 65 years. Circulation. 1995;91(10):2596-604.

41. Gupta AK, Ross EA, Myers JN, Kashyap ML. Increased reverse cholesterol transport in athletes. Metabolism. 1993;42(6):684-90.

42. Nakamura M, Yamamoto Y, Imaoka W, Kuroshima T, Toragai R, Ito Y, et al. Relationships between Smoking Status, Cardiovascular Risk Factors, and Lipoproteins in a Large Japanese Population. J Atheroscler Thromb. 2020.

43. Jain RB, Ducatman A. Associations between smoking and lipid/lipoprotein concentrations among US adults aged >/=20 years. J Circ Biomark. 2018;7:1849454418779310. 
44. van der Gaag MS, van Tol A, Vermunt SH, Scheek LM, Schaafsma G, Hendriks HF. Alcohol consumption stimulates early steps in reverse cholesterol transport. J Lipid Res. 2001;42(12):207783.

45. Brien SE, Ronksley PE, Turner BJ, Mukamal KJ, Ghali WA. Effect of alcohol consumption on biological markers associated with risk of coronary heart disease: systematic review and metaanalysis of interventional studies. BMJ. 2011;342:d636.

46. Traissac P, Pradeilles R, El Ati J, Aounallah-Skhiri H, Eymard-Duvernay S, Gartner A, et al. Abdominal vs. overall obesity among women in a nutrition transition context: geographic and socio-economic patterns of abdominal-only obesity in Tunisia. Popul Health Metr. 2015;13:1.

47. Woudberg NJ, Goedecke JH, Blackhurst D, Frias M, James R, Opie LH, et al. Association between ethnicity and obesity with high-density lipoprotein (HDL) function and subclass distribution. Lipids Health Dis. 2016;15:92.

48. Yu S, Guo X, Li GX, Yang H, Zheng L, Sun Y. Lower or higher HDL-C levels are associated with cardiovascular events in the general population in rural China. Lipids Health Dis. 2020;19(1):152.

49. Dalal JJ, Padmanabhan TN, Jain P, Patil S, Vasnawala H, Gulati A. LIPITENSION: Interplay between dyslipidemia and hypertension. Indian J Endocrinol Metab. 2012;16(2):240-5.

50. Opoku S, Gan Y, Fu W, Chen D, Addo-Yobo E, Trofimovitch D, et al. Prevalence and risk factors for dyslipidemia among adults in rural and urban China: findings from the China National Stroke Screening and prevention project (CNSSPP). BMC Public Health. 2019;19(1):1500.

51. Halperin RO, Sesso HD, Ma J, Buring JE, Stampfer MJ, Gaziano JM. Dyslipidemia and the risk of incident hypertension in men. Hypertension. 2006;47(1):45-50.

52. Tohidi M, Hatami M, Hadaegh F, Azizi F. Triglycerides and triglycerides to high-density lipoprotein cholesterol ratio are strong predictors of incident hypertension in Middle Eastern women. J Hum Hypertens. 2012;26(9):525-32.

53. Steyn K, Fourie J, Benade AJ, Rossouw JE, Langenhoven ML, Joubert G, et al. Factors associated with high density lipoprotein cholesterol in a population with high high density lipoprotein cholesterol levels. Arteriosclerosis. 1989;9(3):390-7.

54. Freedman DS, Srinivasan SR, Shear CL, Franklin FA, Webber LS, Berenson GS. The relation of apolipoproteins $\mathrm{A}-\mathrm{I}$ and $\mathrm{B}$ in children to parental myocardial infarction. N Engl J Med. 1986;315(12):721-6.

55. Hokanson JE, Austin MA. Plasma triglyceride level is a risk factor for cardiovascular disease independent of high-density lipoprotein cholesterol level: a meta-analysis of population-based prospective studies. J Cardiovasc Risk. 1996;3(2):213-9.

56. Bolanos-Garcia VM, Miguel RN. On the structure and function of apolipoproteins: more than a family of lipid-binding proteins. Prog Biophys Mol Biol. 2003;83(1):47-68.

57. Walldius G, Jungner I. The apoB/apoA-I ratio: a strong, new risk factor for cardiovascular disease and a target for lipid-lowering therapy-a review of the evidence. J Intern Med. 2006;259(5):493-519. 
Figures

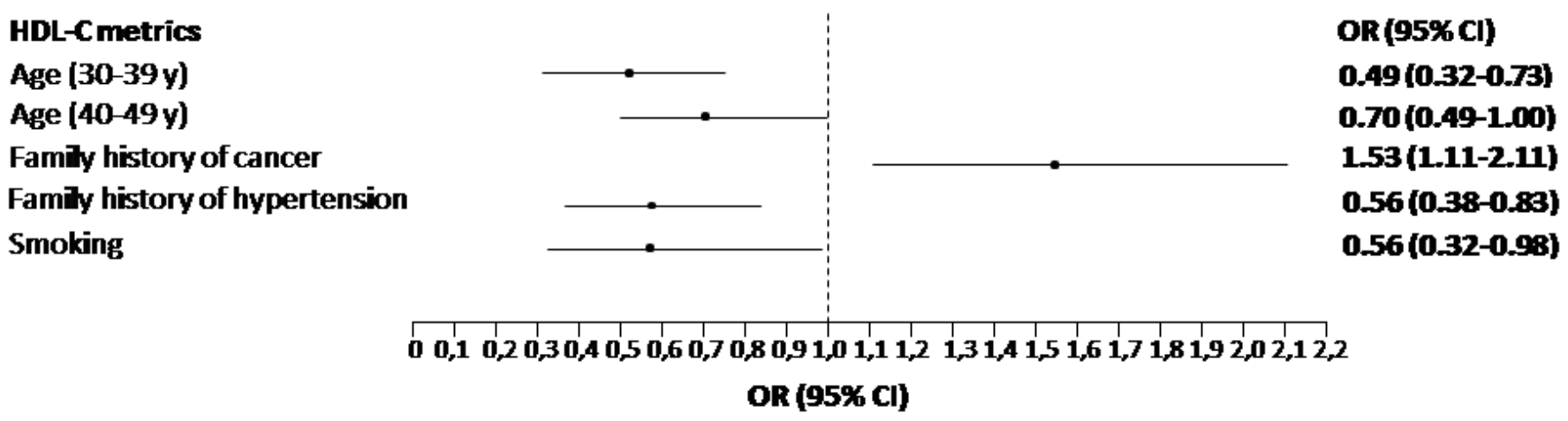

Figure 1

Adjusted odds ratio (OR; $95 \% \mathrm{Cl}$ ) of $\mathrm{HDL}-\mathrm{C}$ for age and all socio-demographic, lifestyle and biological factors. 